\title{
PROXIMITY RING FED MULTIBAND PRINTED MONOPOLE FRACTAL ANTENNA
}

\author{
Yogesh Babaraoji Thakare \\ Department of E\&TC Engineering, \\ PVG's COET, Pune Affiliated to Savitribai Phule Pune University, Pune, India
}

\begin{abstract}
Small antennas satisfying bandwidth requirements in wideband, broadband and multichannel communication systems are of wide interest among researchers. This paper investigates the resonant behaviour of proximity coupled circular fractal planar monopole against circular fractal planar monopole without proximity coupling. The antennas are fed using microstripline and coplanar waveguide technique. These antennas are designed and printed on low cost FR4 substrate ( height $h=1.56 \mathrm{~mm}$ and $\varepsilon_{r}=4.3$ ) of size $110 \mathrm{~mm}$ by $115 \mathrm{~mm}$ with circular patch radius of $40 \mathrm{~mm}$. The planar fractal monopole shows multiband characteristics under different configurations of feed. The monopole can be used for various compact applications in $482 \mathrm{MHz}$ to $4 \mathrm{GHz}$ band.
\end{abstract}

\section{KEYWORDS}

Antenna, bandwidth enhancement, compact, fractal, iterative, monopole, multiband, proximity.

\section{INTRODUCTION}

There is a continuing interest in broadband (BW 2:1) antennas operating over a wide frequency range to satisfy high data rates in second to fifth generations of communication technologies for multimedia applications. These systems need low-cost compact antennas with desired performance characteristics. Few of the examples of such systems are mobile systems in the second generation (2G) viz. GSM1800 and GSM1900, operating in the frequency bands 1710 $1880 \mathrm{MHz}$ and 1850-1990 MHz, third generation (3G) systems viz. cdma-2000, WCDMA, and TD-SCDMA operating in frequency band 1920-2170 MHz.

A number of recent books [1-2] and articles [3-15] have surveyed various bandwidth enhancement techniques. The structural technique for enhancement of bandwidth of an antenna is continuously evolving. Initially, it has involved primarily the antenna substrate. Now days both the antenna substrate and its geometry have been targeted towards bandwidth enhancement. Microstrip patches are modified in shape and incorporated with slots of various sizes and shapes. The impedance matching techniques using the circuit theory approach are reported for bandwidth enhancement [1-2]. To facilitate the increased demand for bandwidth, the planar monopoles using printed circuit boards are also playing important role in various wireless communication applications due to their low manufacturing cost, and easy integration into planar circuits.

DOI: $10.5121 /$ jant.2016.2401 
This paper has investigated bandwidth enhancement in proximity coupled printed circular planar fractal monopole antenna against the printed circular planar fractal monopole without proximity coupling.

\section{DESIGN OF ANTENNA}

The designed antenna is a modification of Sierpinski triangular geometry incorporated in a conventional circular microstrip patch antenna (CMPA) on iterative basis using a designed fractal generator $[13,15-16]$. The fractal generator has been designed by subtracting equilateral triangle of dimensions $73.5 \mathrm{~mm}$ three times from a circle of radius, $\mathrm{r}=40 \mathrm{~mm}$ as shown in Fig. 1. This subtraction can be done in three steps 1 . Subtract the triangle from circle with vertex of triangle at 0 deg., 2. Subtract triangle with vertex at $90 \mathrm{deg}$. from the geometry generated in step 1, 3 . Subtract triangle with vertex at $180 \mathrm{deg}$. from the geometry generated in step 2 . The copper patch has been designed using this generator. This patch is scaled down 4 times to be included in the larger size iteration i.e. $2^{\text {nd }}$ iteration is accommodated in $1^{\text {st }}$ iteration, $3^{\text {rd }}$ in $2^{\text {nd }}$ iteration and $4^{\text {th }}$ in $3^{\text {rd }}$ iteration to design 4 th iterated fractal antenna geometry as shown in Fig. 2.

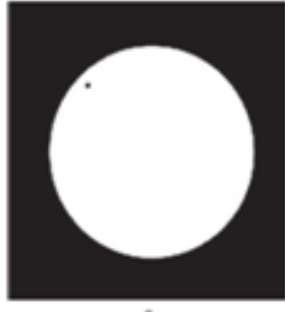

Conventional

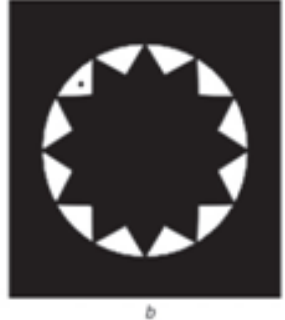

$1^{\text {st }}$ Iteration

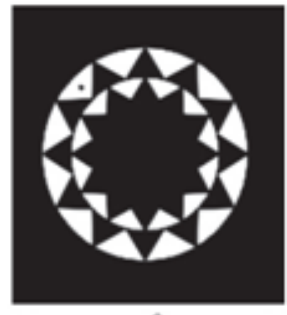

$2^{\text {nd }}$ Iteration

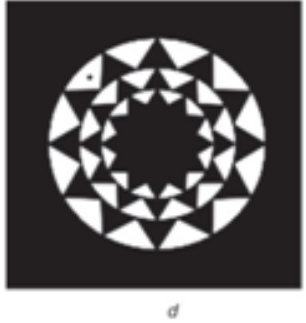

$3^{\text {rd }}$ Iteration

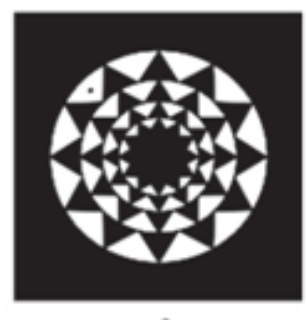

$4^{\text {th }}$ Iteration

Figure 1. Design of proposed fractal circular microstrip antenna [13, 15-16].

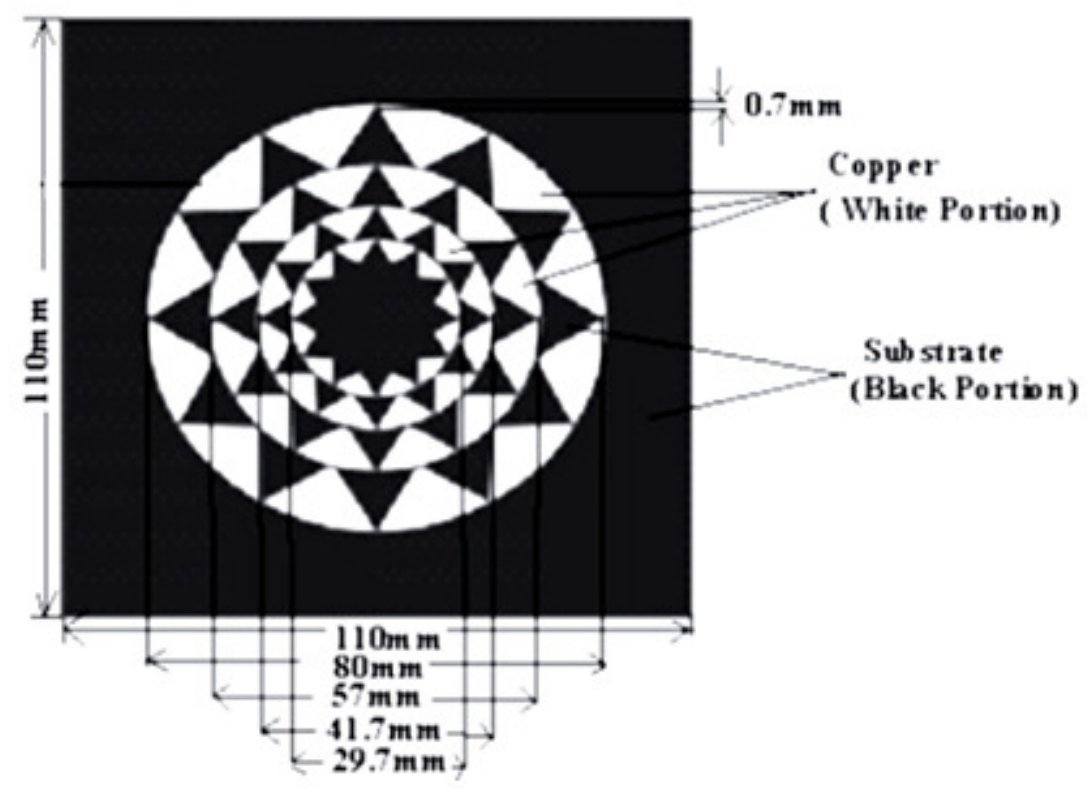

Figure 2. Design of fourth iteration proposed fractal patch [13, 15-16]. 
A planar fractal printed monopole using this fourth iterated patch has been fabricated on low cost FR4 $\left(\varepsilon_{\mathrm{r}}=4.3 \mathrm{~h}=1.56 \mathrm{~mm}\right)$ substrate (size: $110 \mathrm{~mm}$ by $\left.115 \mathrm{~mm}\right)$ and fed using 1 . simple $50 \Omega$ microstrip transmission line with partial and full background, $2.1 \mathrm{~mm}$ thick proximity ring with $50 \Omega$ microstrip transmission line with partial background, and $3.1 \mathrm{~mm}$ thick proximity ring with $50 \Omega$ coplanar waveguide feed with partial background as shown in Fig. 3, Fig. 4 and Fig. 5.

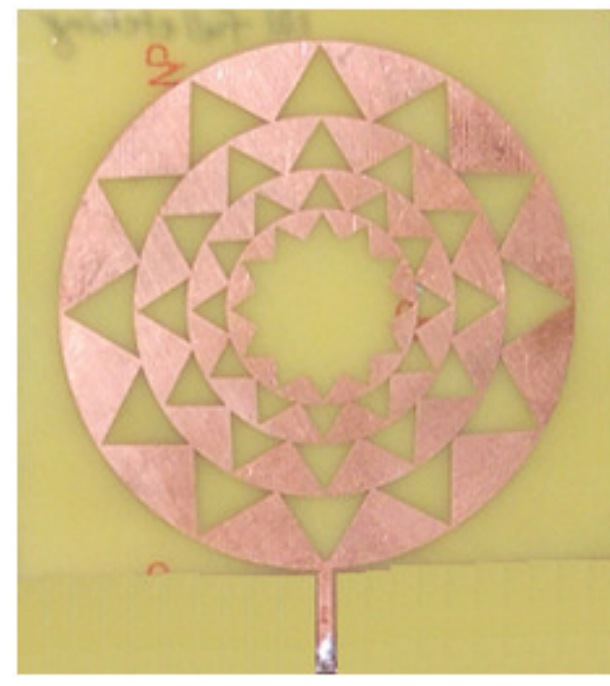

Front view

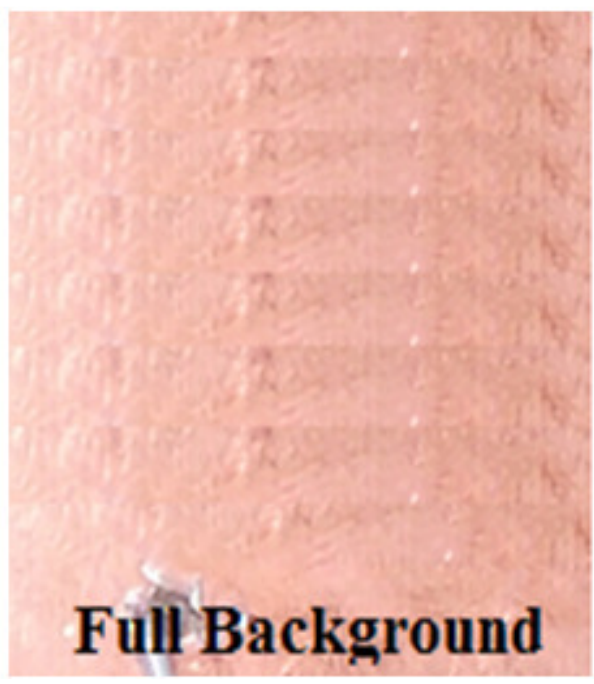

Rear View

Figure 3a. Printed circular fractal planar monopole on FR4 substrate fed using $50 \Omega$ microstrip line with full background.
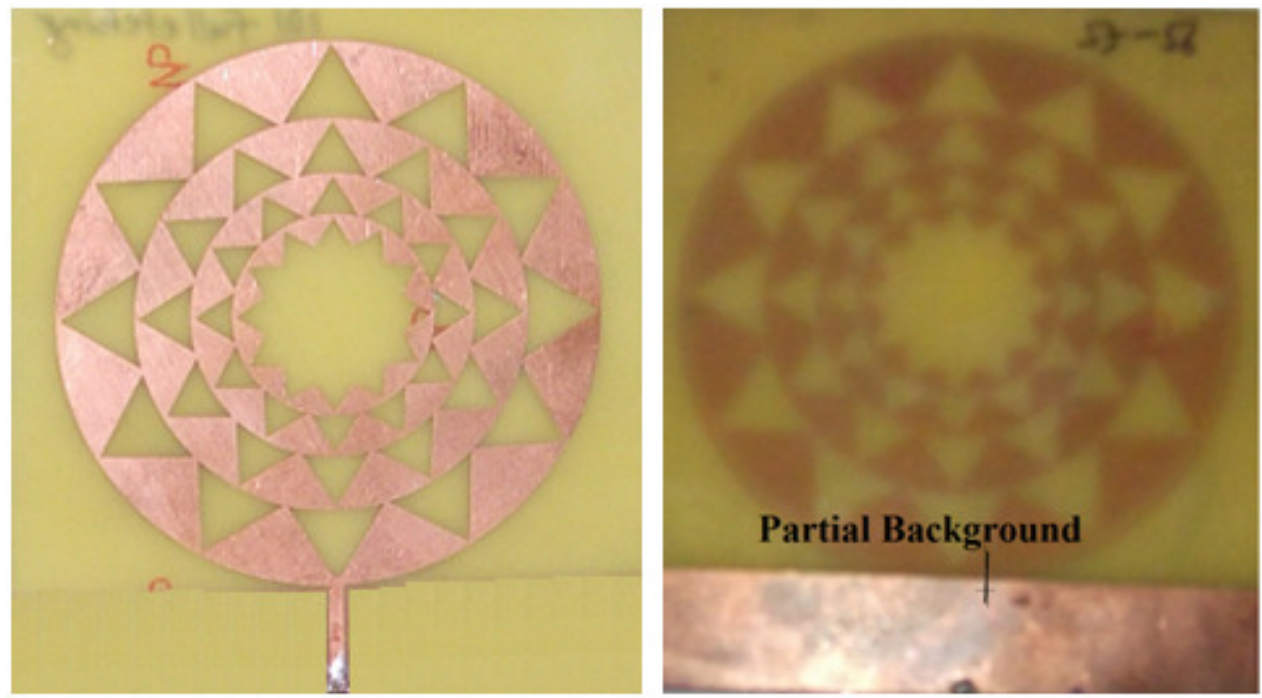

Figure $3 b$. Printed circular fractal planar monopole on FR4 substrate fed using $50 \Omega$ microstrip line with partial background. 
International Journal of Antennas (JANT) Vol.2, No.4, October 2016

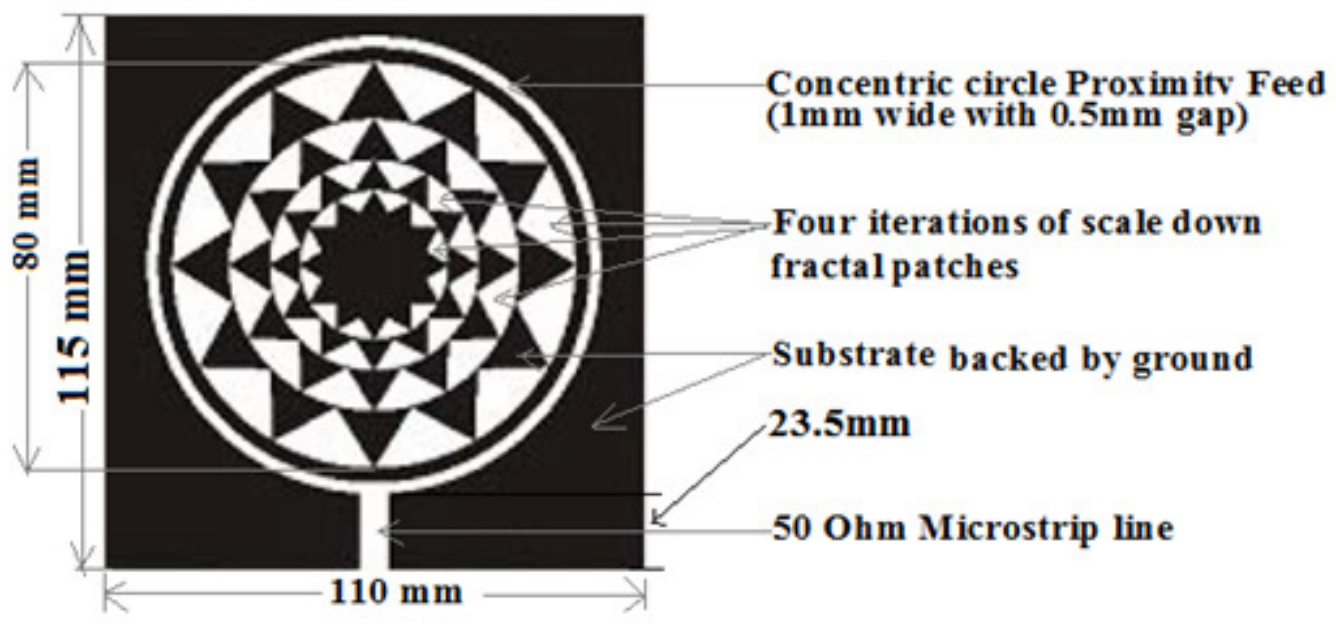

Figure 4a. Design of printed circular fractal planar monopole fed using concentric proximity ring $(1 \mathrm{~mm}$ wide with $0.5 \mathrm{~mm}$ gap) and $50 \Omega$ microstrip line on FR4 substrate.

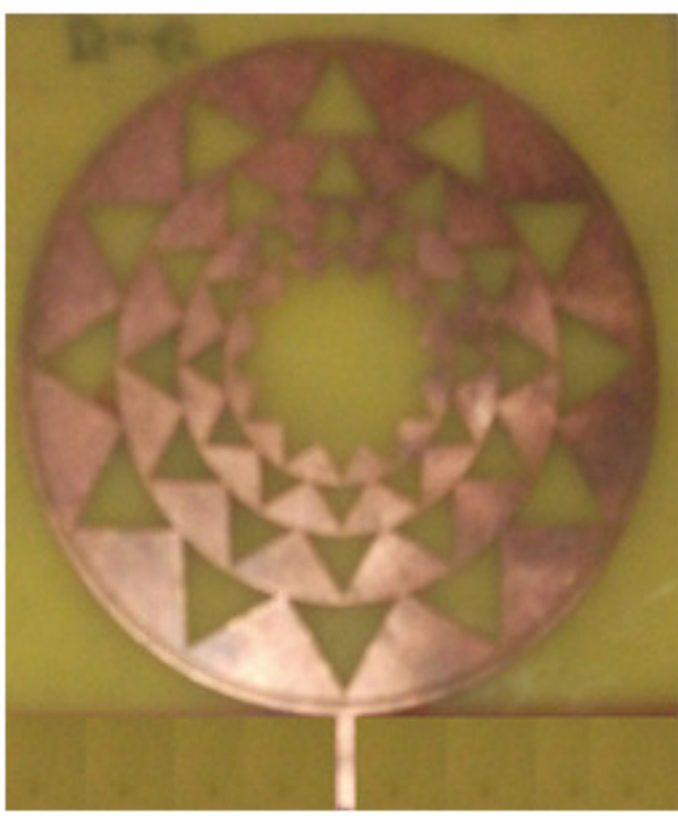

Front view

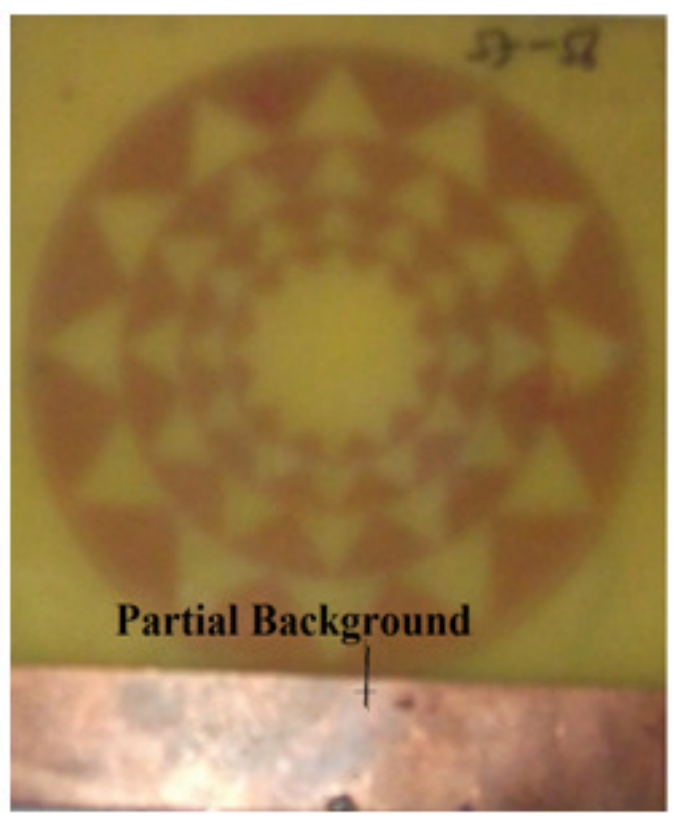

Rear View

Figure 4b. Photograph of printed circular fractal planar monopole fed using concentric proximity ring ( $1 \mathrm{~mm}$ wide with $0.5 \mathrm{~mm}$ gap) and $50 \Omega$ microstrip line on FR4 substrate. 


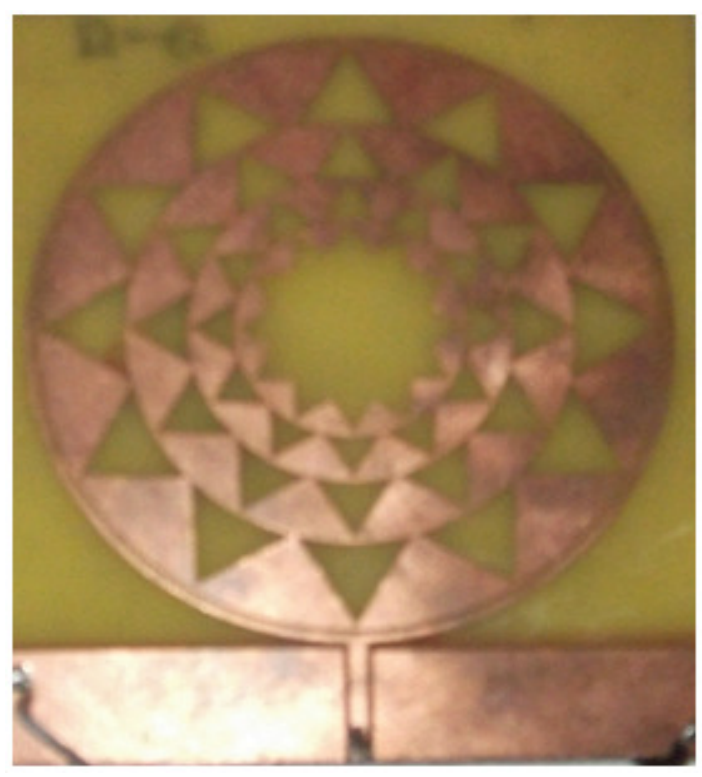

Front view

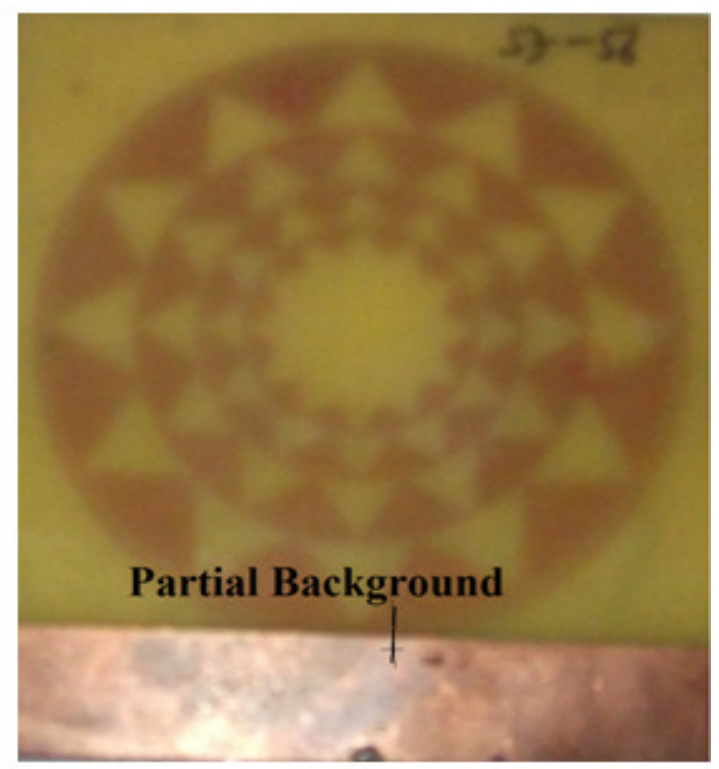

Rear View

Figure 5. Printed circular fractal planar monopole fed using concentric proximity ring ( $1 \mathrm{~mm}$ wide with $0.5 \mathrm{~mm}$ gap) and $50 \Omega \mathrm{CPW}$ line on FR4 substrate.

\section{RESULTS AND DISCUSSIONS}

\subsection{Reflection loss}

The reflection loss or reflection coefficient pattern against varying frequency of the printed circular fractal planar monopole fed using simple $50 \Omega$ microstripline as seen in Fig. 3a (with full background) is simulated and measured. The results are compared in Fig. 6. Both, simulated and measured results are in close agreement with some tolerance. These results clearly indicate the multiband nature of the monopole. The multiband behaviour of the monopole can be attributed to self similar iterative fractal nature of the patch. Further, the space filling nature of the monopole antenna geometry [15] reduces the size of the antenna to become independent of the size dependent resonance. The resonant frequencies in the antenna are a function of iteration depth. Increasing iteration depth increases the space filling properties of the fractal patch to affect compactness in the printed fractal monopole [15]. The measured results of the printed circular fractal planar monopole fed using simple $50 \Omega$ microstripline with full background (Fig. 3a ) and partial (Fig. 3b) are compared in Fig. 7. The results show that printed fractal monopole in both the configurations behaves as multiband antenna. But, with partial ground, the bandwidth associated with multiple bands becomes wider than with full background. The perturbation in the bandwidth with background size is attributed to wider impedance matching as seen in Fig. 8a and Fig. 8b with partial background as compared to full background. The partial background couples the multiple resonances to justify the broader bandwidth. Further, these coupling effects are not uniform across the multiple bands. Table 1 shows the variation in bandwidth with partial and full background in planar circular fractal monopole. With full background, the printed fractal monopole exhibits maximum bandwidth of $2.95 \%$ (at $-10 \mathrm{~dB}$ reflection coefficient) compared to 
International Journal of Antennas (JANT) Vol.2, No.4, October 2016

maximum $63.50 \%$ (at $-10 \mathrm{~dB}$ reflection coefficient) with partial background as seen from Table 1. Further, the microstripline fed printed circular planar fractal monopole with partial background exhibits a dual band antenna with wideband properties.

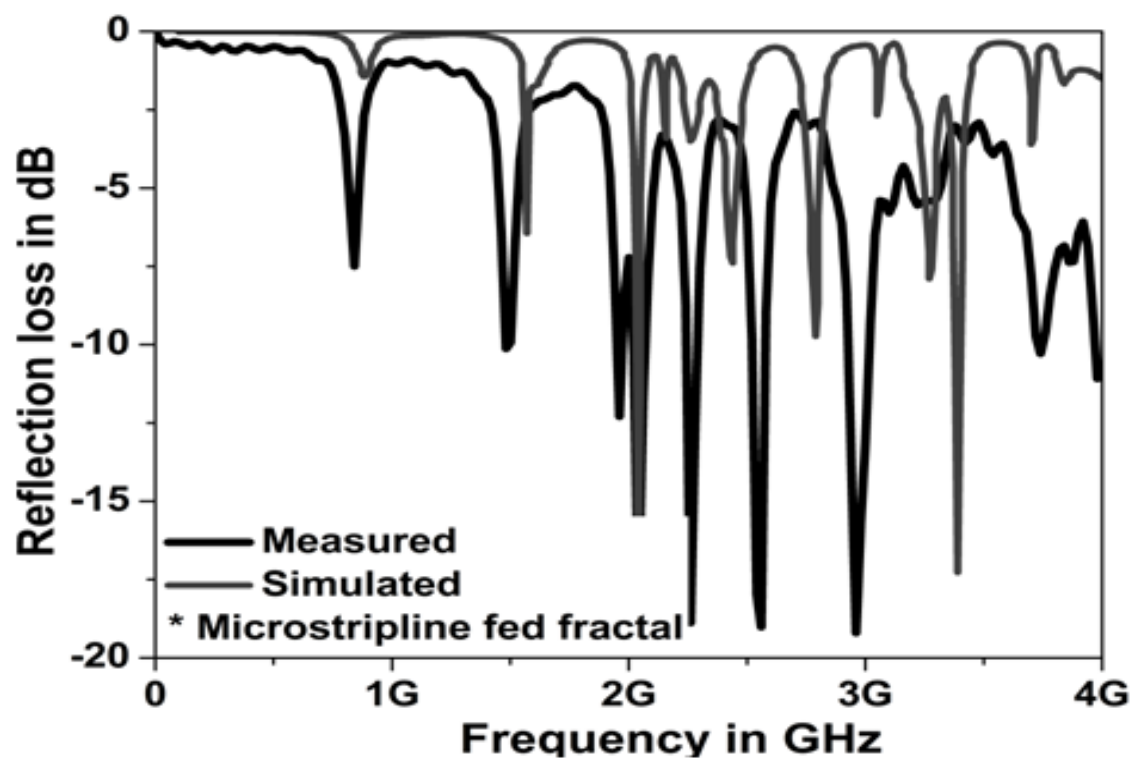

Figure 6. Measured and simulated reflection loss plot of microstripline fed printed circular planar fractal monopole without proximity ring.

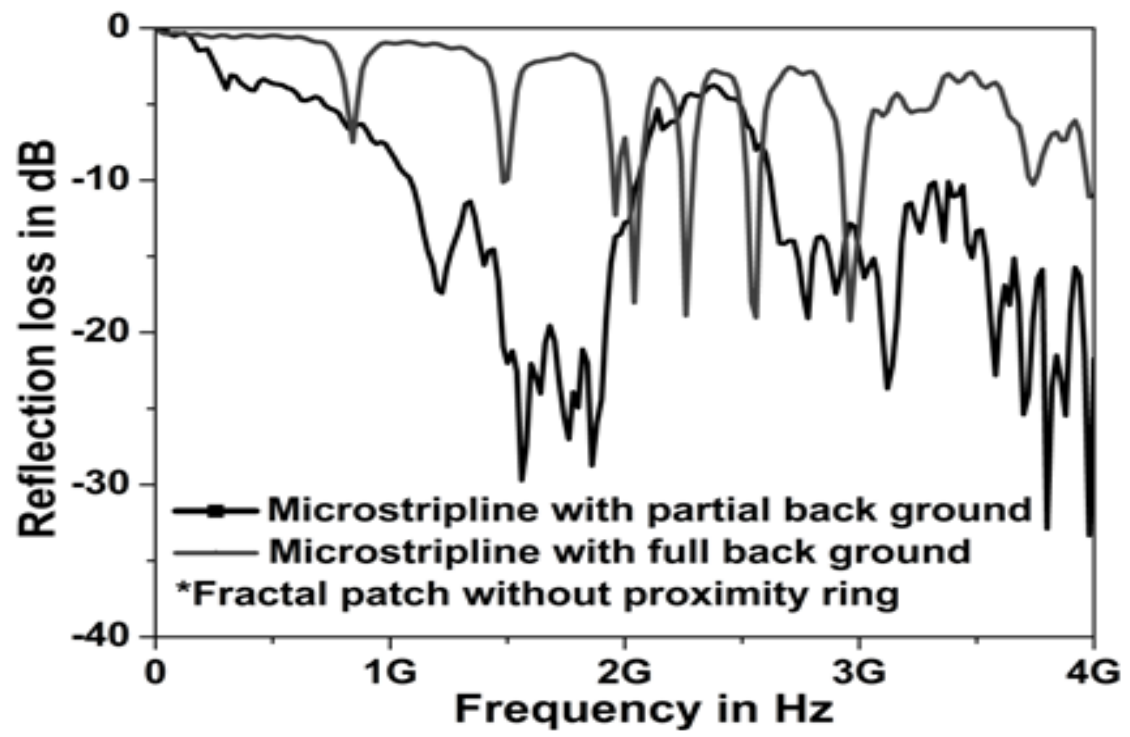

Figure 7. Effect of ground size on the reflection loss bandwidth exhibited by microstripline fed printed circular planar fractal monopole. 
International Journal of Antennas (JANT) Vol.2, No.4, October 2016

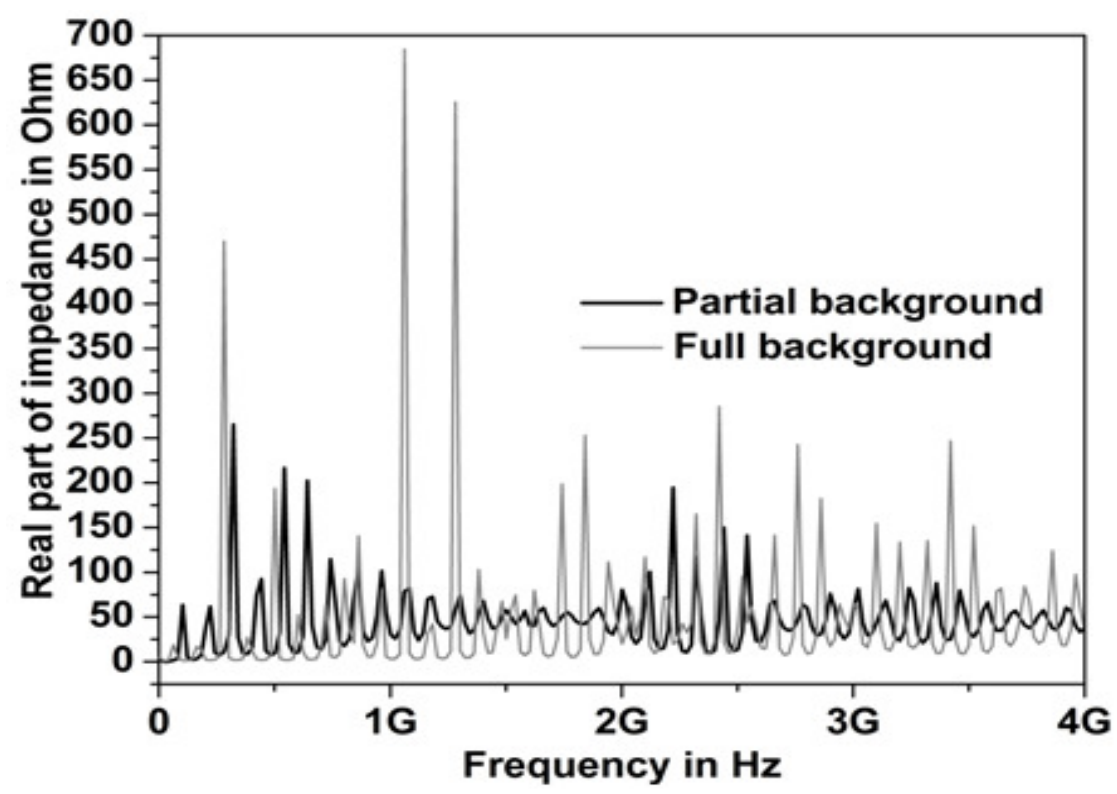

Figure 8a. Effect of ground size on real part of impedance exhibited by microstripline fed printed circular planar fractal monopole without proximity ring.

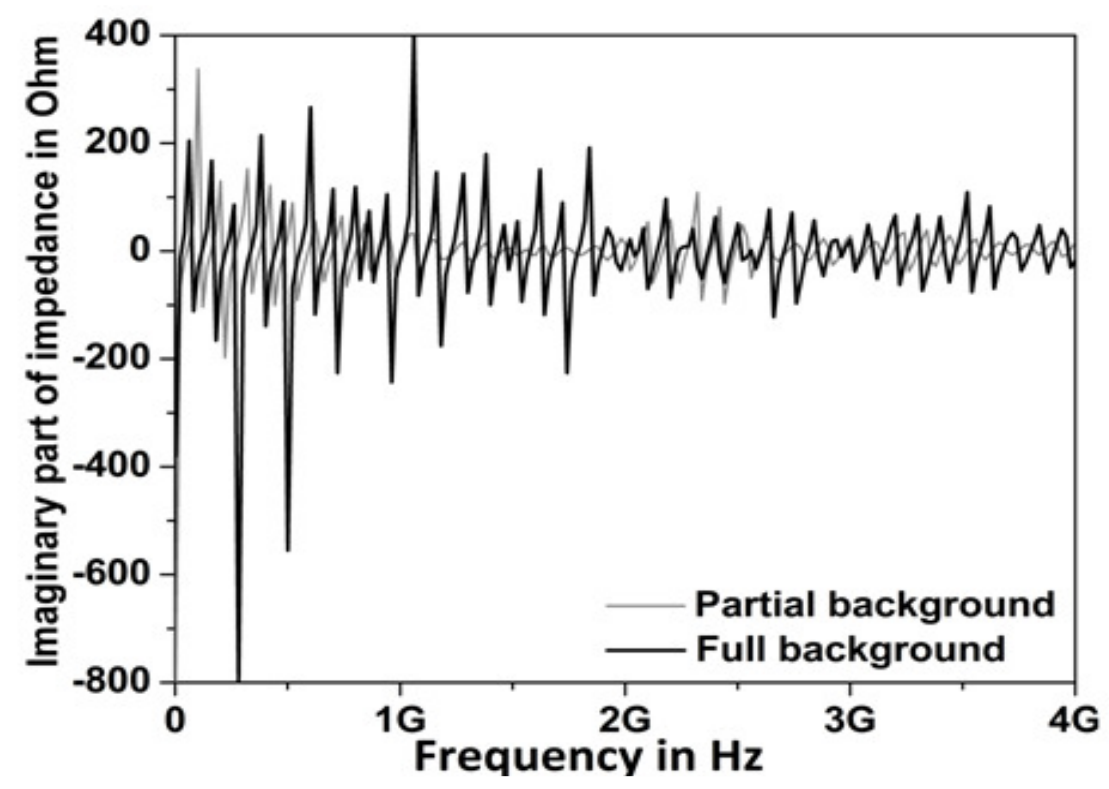

Figure 8b. Effect of ground size on imaginary part of impedance exhibited by microstripline fed printed circular planar fractal monopole without proximity ring. 
International Journal of Antennas (JANT) Vol.2, No.4, October 2016

Table 1, Effect of ground size on the bandwidth exhibited by microstrpline fed printed circular planar fractal monopole without proximity ring.

\begin{tabular}{|c|c|c|c|c|c|}
\hline \multicolumn{6}{|c|}{$\begin{array}{c}\text { Microstripline Fed (Full Background) } \\
\text { Printed Circular Planar Fractal Monopole }\end{array}$} \\
\hline $\begin{array}{l}\text { Resonant Freq. } \\
\text { in GHz at }-5 \mathrm{~dB}\end{array}$ & 0.8316 & 1.481 & 2.011 & 2.99 & 3.81 \\
\hline$\Delta \mathrm{f}=\mathrm{fh}-\mathrm{fl}(\mathrm{GHz})$ & 0.0608 & 0.08 & 0.179 & 0.26 & 0.38 \\
\hline$\% \mathrm{BW}(\mathrm{GHz})$ & 7.3112 & 5.4017 & 8.9032 & 8.6956 & 9.9737 \\
\hline $\begin{array}{l}\text { Resonant Freq. } \\
\text { in } \mathrm{GHz} \text { at }-10 \mathrm{~dB}\end{array}$ & - & 1.4813 & 2.03 & 2.96 & - \\
\hline$\Delta \mathrm{f}=\mathrm{fh}-\mathrm{fl}(\mathrm{GHz})$ & - & 0.04 & 0.06 & 0.08 & - \\
\hline$\% \mathrm{BW}(\mathrm{GHz})$ & - & 2.7 & 2.9556 & 2.7027 & - \\
\hline \multicolumn{6}{|c|}{$\begin{array}{l}\text { Microstripline Fed (Partial Background) } \\
\text { Printed Circular Planar Fractal Monopole }\end{array}$} \\
\hline $\begin{array}{l}\text { Resonant Freq. } \\
\text { in GHz at }-5 \mathrm{~dB}\end{array}$ & 1.4805 & 3.23 & - & - & - \\
\hline$\Delta \mathrm{f}=\mathrm{fh}-\mathrm{fl}(\mathrm{GHz})$ & 1.559 & 1.54 & - & - & - \\
\hline$\%$ BW ( GHz) & 105.302 & 47.678 & - & - & - \\
\hline $\begin{array}{l}\text { Resonant Freq. } \\
\text { in GHz at }-10 \mathrm{~dB}\end{array}$ & 1.5385 & 3.31 & - & - & - \\
\hline$\Delta \mathrm{f}=\mathrm{fh}-\mathrm{fl}(\mathrm{GHz})$ & 0.977 & $>1.38$ & - & - & - \\
\hline$\% \mathrm{BW}(\mathrm{GHz})$ & 63.5034 & $>41.692$ & - & - & - \\
\hline
\end{tabular}

Now, the printed circular fractal planar monopole is fed using a gap coupled proximity ring with $50 \Omega$ microstripline (Fig. 4b) and the measured results are obtained. These results are compared with planar circular fractal monopole without the proximity ring (Fig. 3b) in Fig. 9. The lower frequency shift is observed in proximity ring microstripline fed (partial back ground) monopole compared to without proximity ring microstripline fed (full background) monopole from 0.860 $\mathrm{GHz}$ to $0.681 \mathrm{GHz}$. This indicates that incorporation of proximity ring and gap coupling increases the size of the monopole to effect lower frequency shift. Further, the bandwidth in multiple bands changes with background size as well as inclusion of proximity ring to indicate their impact on coupled resonance (Fig. 7 and Fig. 8). The proximity concentric ring around the antenna geometry with $50 \mathrm{ohm}$ transmission line feed increases the bandwidth around the centre frequencies at $0.681 \mathrm{GHz}, 2.21 \mathrm{GHz}, 2.94 \mathrm{GHz}, 3.36 \mathrm{GHz}$ compared to $0.860 \mathrm{GHz}, 2.41 \mathrm{GHz}$, $3.11 \mathrm{GHz}, 3.94 \mathrm{GHz}$ with microstripline without proximity ring.

The improvement in bandwidth has been reported in Table 2 . The maximum of $20 \%$ bandwidth has been noted with gap coupled proximity ring microstripline fed (partial background) planar fractal printed monopole compared to $2.9 \%$ in microstripline fed (full background) without proximity ring.Further, the proximity ring planar fractal monopole is fed with $50 \Omega \mathrm{CPW}$ line. The measured and simulated results are obtained in Fig. 10 to find a close match between them. These results are compared with microstripline fed (partial background) proximity ring planar circular fractal monopole as shown in Fig. 11. The CPW fed monopole has exhibited multiband properties with small bandwidth improvements around the same resonating frequencies compared to microstripline. This indicates that there is minimum impact on coupled resonance of micropstripline or CPW feed when printed monopole is gap coupled using proximity ring. 
International Journal of Antennas (JANT) Vol.2, No.4, October 2016

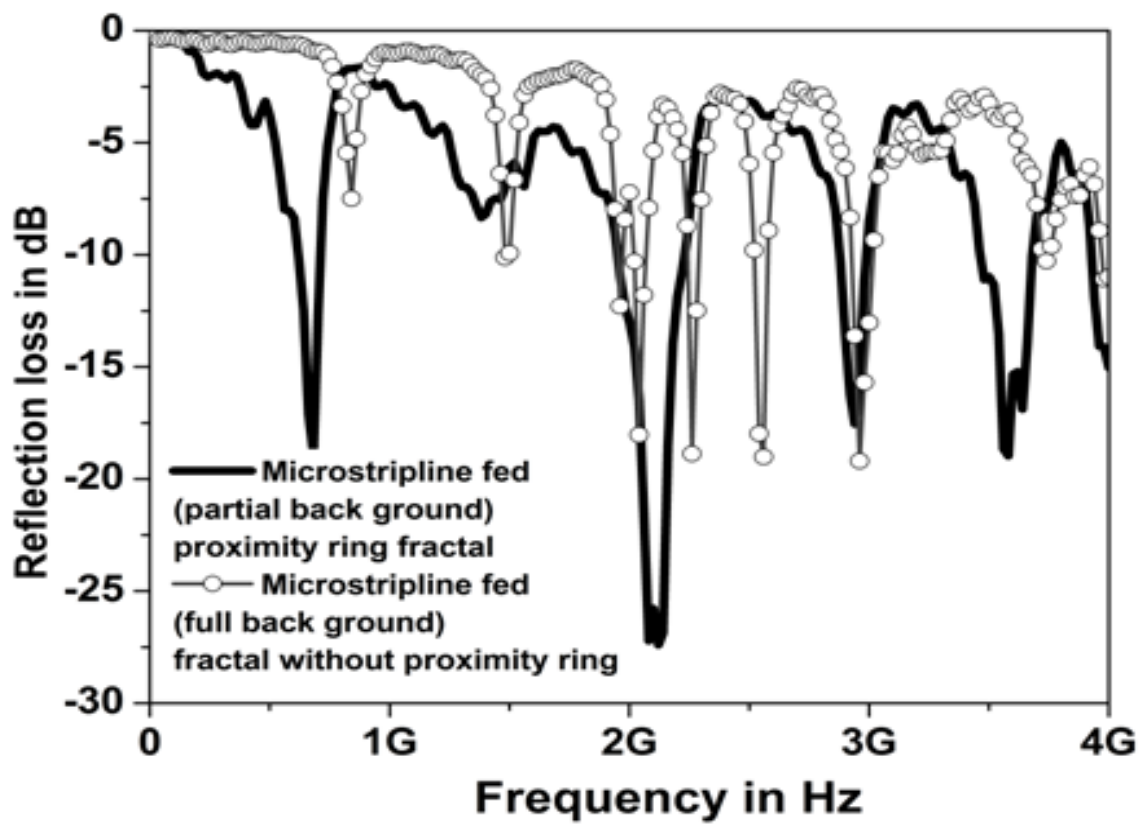

Figure 9. Comparative reflection loss plot of printed circular planar fractal monopole fed using microstripline with proximity ring and without proximity ring.

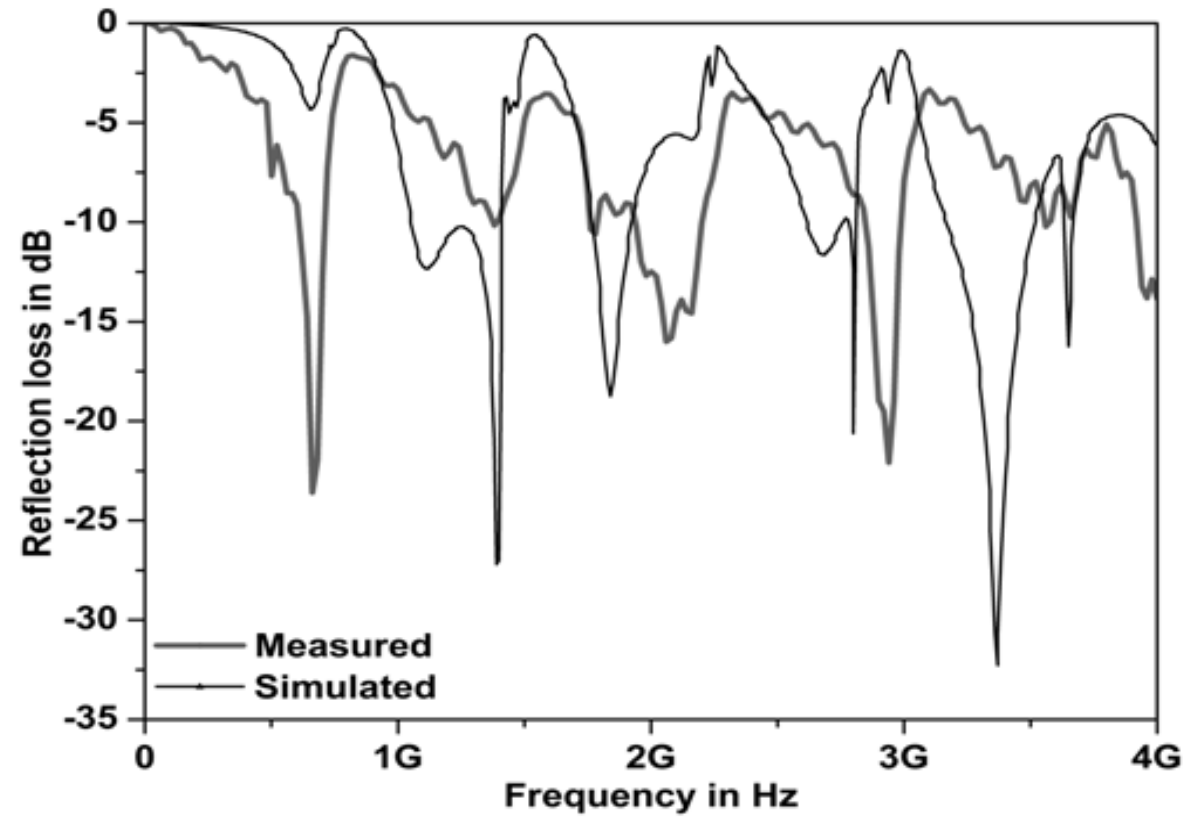

Figure 10. Measured and simulated reflection loss plot of CPW fed proximity ring printed circular planar fractal monopole. 
International Journal of Antennas (JANT) Vol.2, No.4, October 2016

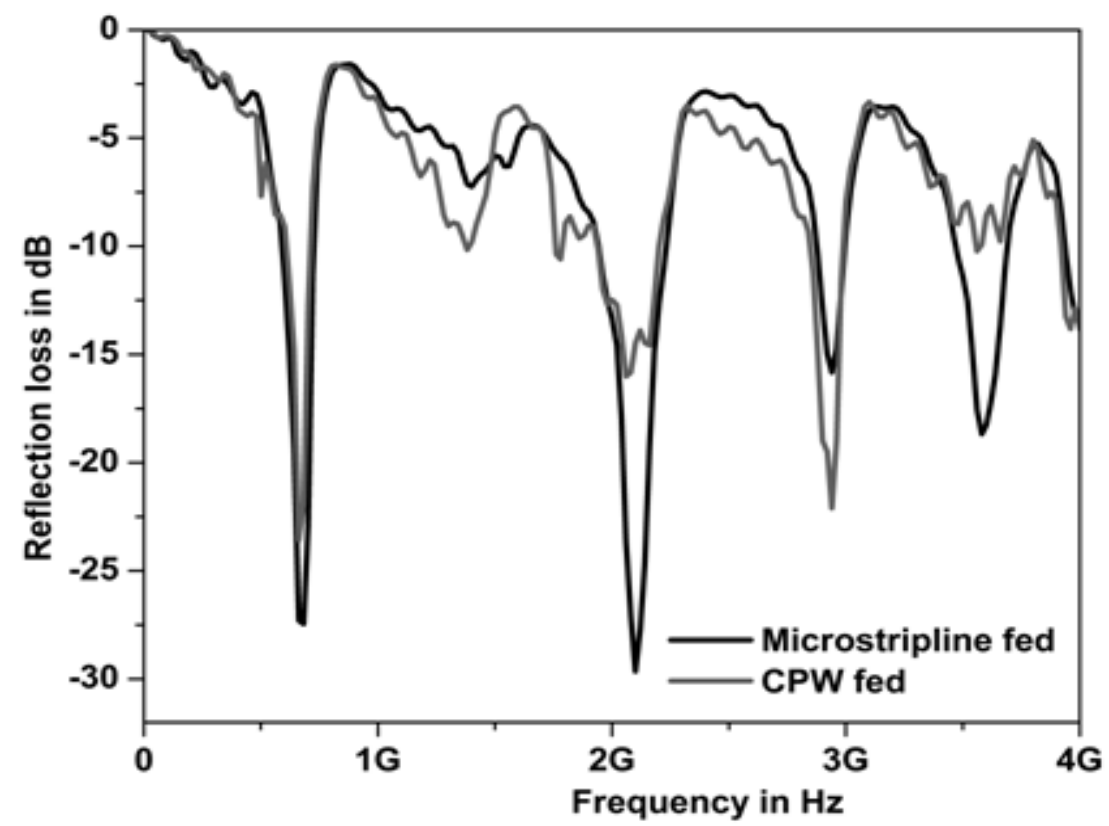

Figure 11. Comparative reflection loss plot of printed circular planar fractal monopole fed using microstripline and CPW feed with proximity ring.

The imaginary and real part of impedance for proximity ring fed fractal monopole using microstripline and CPW feed have been plotted in Fig. 12a and Fig. 12b.

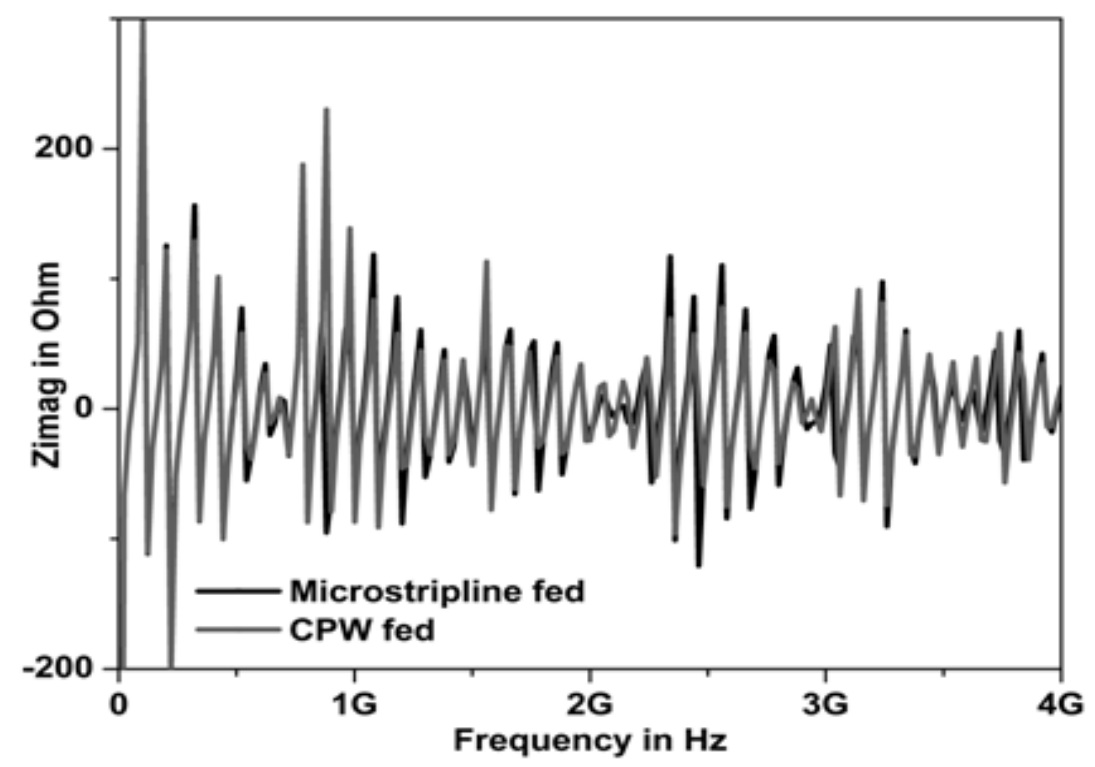

Figure 12a. Imaginary part of impedance for proximity ring printed circular planar fractal monopole fed using microstripline and CPW. 
International Journal of Antennas (JANT) Vol.2, No.4, October 2016

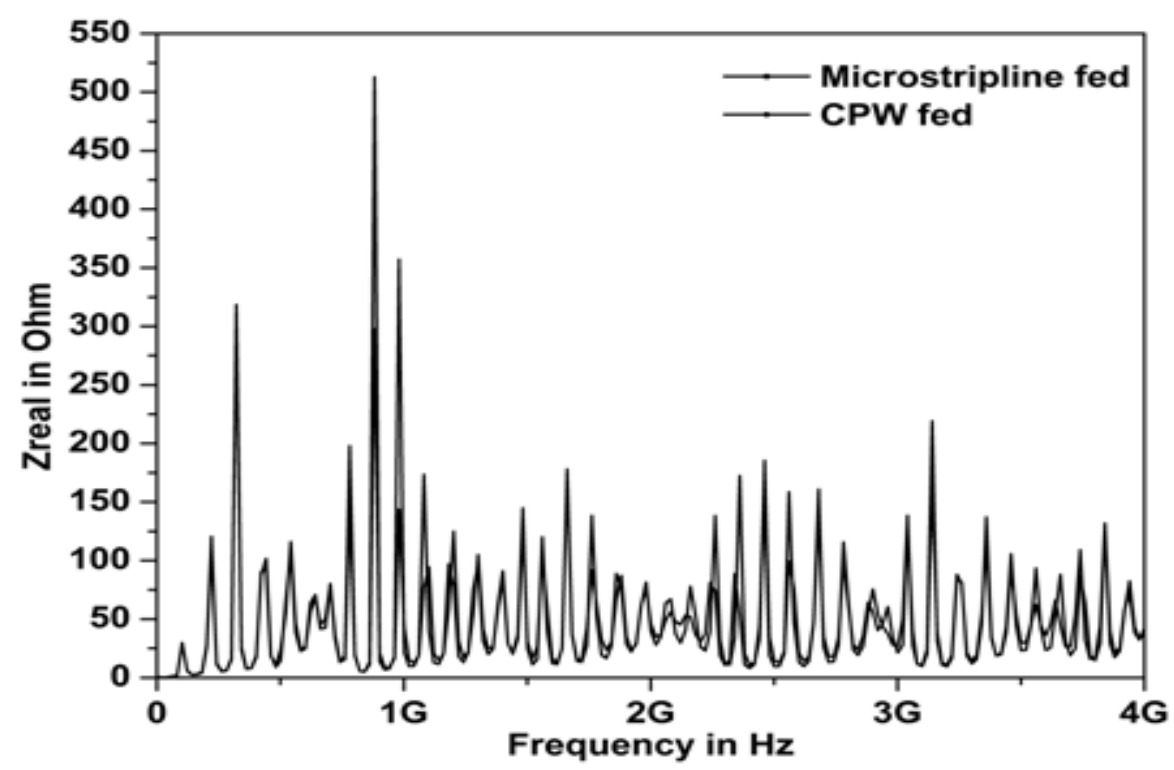

Figure 12b. Real part of impedance for proximity ring printed circular planar fractal monopole fed using microstripline and CPW.

Around resonant frequencies, the reactive part minimizes and real part approaching towards 50 ohm compared to other frequencies to improve impedance matching to enhance the bandwidth in the monopole. Maximum of $12.56 \%(-10 \mathrm{~dB})$ bandwidth has been reported with CPW feed in proximity ring planar fractal monopole as shown in Table 2.

Table 2, Bandwidth improvement in printed circular planar fractal monopole using gap coupled proximity ring with microstripline and $\mathrm{CPW}$ line feed techniques.

\begin{tabular}{|c|c|c|c|c|c|}
\hline \multicolumn{6}{|c|}{$\begin{array}{c}\text { Microstripline Fed (Partial Background) Proximity Ring } \\
\text { Printed Circular Planar Fractal Monopole }\end{array}$} \\
\hline $\begin{array}{l}\text { Resonant Freq. in } \\
\text { GHz at }-5 \mathrm{~dB}\end{array}$ & 0.6365 & 1.43 & 1.975 & 2.91 & 3.66 \\
\hline$\Delta \mathrm{f}=\mathrm{fh}-\mathrm{fl}(\mathrm{GHz})$ & 0.229 & 0.34 & 0.65 & 0.30 & 0.68 \\
\hline$\% \mathrm{BW}(\mathrm{GHz})$ & 35.98 & 23.78 & 32.91 & 10.31 & 18.57 \\
\hline $\begin{array}{l}\text { Resonant Freq. in } \\
\text { GHz at -10dB }\end{array}$ & 0.671 & - & 2.09 & 2.94 & 3.59 \\
\hline$\Delta \mathrm{f}=\mathrm{fh}-\mathrm{fl}(\mathrm{GHz})$ & 0.140 & - & 0.3 & 0.12 & 0.22 \\
\hline$\% \mathrm{BW}(\mathrm{GHz})$ & 20.86 & - & 14.35 & 4.08 & 6.1 \\
\hline \multicolumn{6}{|c|}{$\begin{array}{c}\text { CPW Fed (Partial Background) } \\
\text { Printed Circular Planar Fractal Monopole }\end{array}$} \\
\hline $\begin{array}{l}\text { Resonant Freq. in } \\
\text { GHz at }-5 \mathrm{~dB}\end{array}$ & 0.612 & 1.291 & 1.98 & 2.91 & 3.63 \\
\hline$\Delta \mathrm{f}=\mathrm{fh}-\mathrm{fl}(\mathrm{GHz})$ & 0.26 & 0.42 & 0.6 & 0.3 & 0.74 \\
\hline$\% \mathrm{BW}(\mathrm{GHz})$ & 42.48 & 32.5 & 30.30 & 10.31 & 20.38 \\
\hline $\begin{array}{l}\text { Resonant Freq. in } \\
\text { GHz at -10dB }\end{array}$ & 0.662 & - & 2.07 & 2.91 & -- \\
\hline$\Delta \mathrm{f}=\mathrm{fh}-\mathrm{fl}(\mathrm{GHz})$ & 0.08 & - & 0.26 & 0.14 & - \\
\hline$\% \mathrm{BW}(\mathrm{GHz})$ & 12 & - & 12.56 & 4.811 & - \\
\hline
\end{tabular}




\subsection{RADIATION PATTERNS}

The radiation pattern of the proximity ring fractal antenna fed using microstripline and CPW technique in azimuthal plane at 0 deg. elevation for four resonant frequencies have been shown in Fig. 13 and Fig. 14 respectively. These patterns are similar and nearly omni-directional at all the resonant frequencies. The maximum gains of $2.625 \mathrm{~dB}$ using microstripline and around $0 \mathrm{~dB}$ using CPW have been observed.

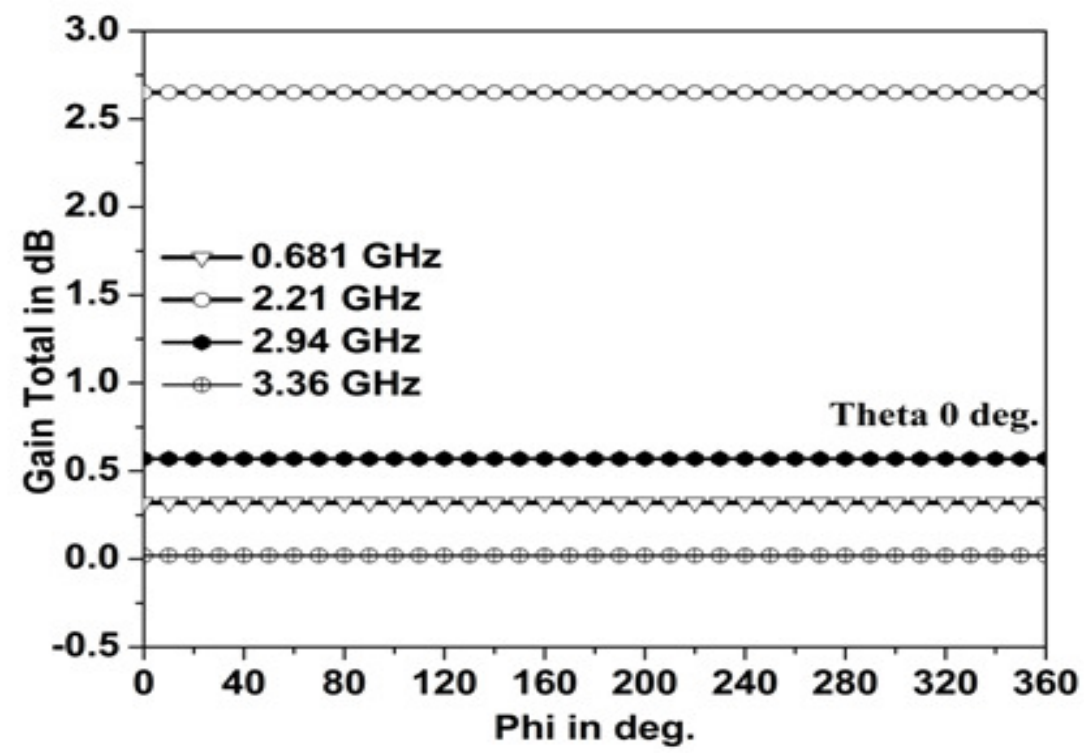

Figure 13. Gain Total vs. azimuth plot for microstripline fed proximity ring printed circular planar fractal monopole at various resonant frequencies

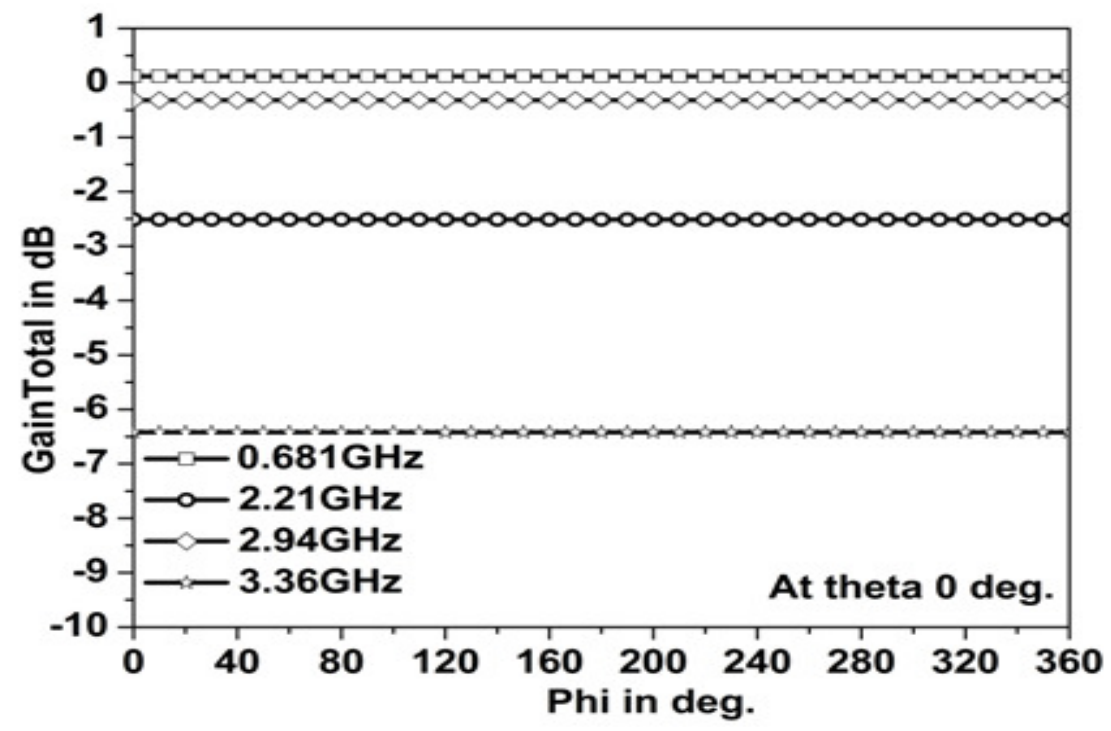

Figure 14. GainTotal vs. azimuth plot for CPW fed proximity ring printed circular planar fractal monopole at various resonant frequencies. 
To obtain further insight, the radiation patterns have been studied comparatively in azimuth as well as elevation plane at one of the resonant frequency $0.681 \mathrm{GHz}$ for both microstripline and CPW as shown in Fig. 15 and Fig. 16. These patterns show changes in orientation with change in feed from microstripline to CPW keeping shape nearly similar with slight distortions in respective planes. The patterns are either omini-directional or bidirectional in azimuthal plane where as unidirectional in elevation plane with microstrip as well as CPW feed.

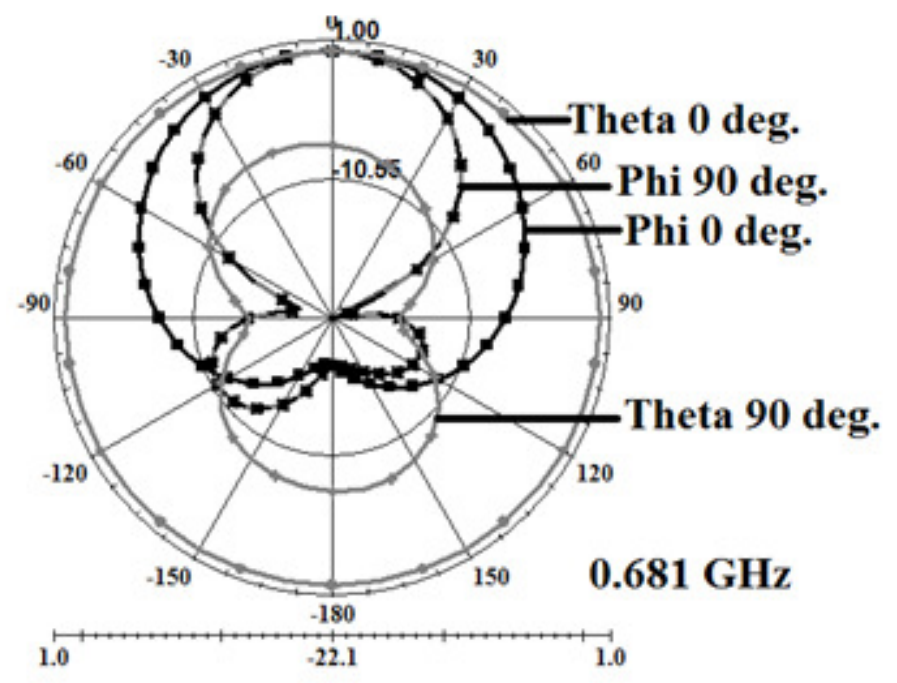

Figure 15. GainTotal plot for microstripline fed proximity ring printed circular planar fractal monopole at resonant frequency $0.681 \mathrm{GHz}$.

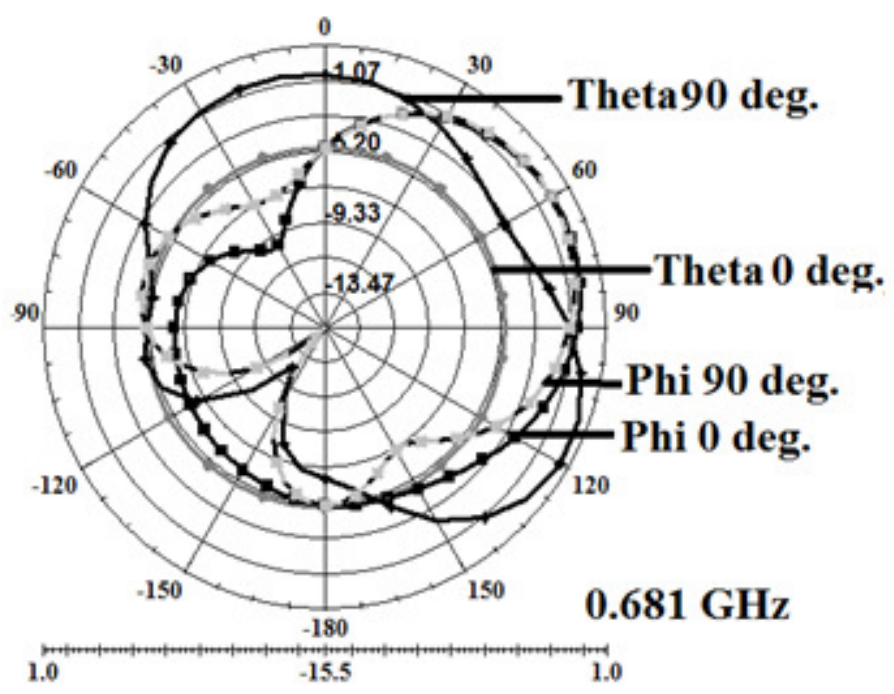

Figure 16. GainTotal plot for CPW fed proximity ring printed circular planar fractal monopole at resonant frequency $0.681 \mathrm{GHz}$. 


\section{CONCLUSIONS}

The paper emphasizes bandwidth enhancement process in printed planar circular fractal monopole. The planar circular fractal monopole with gap coupled proximity ring shows multiband bandwidth enhancement using microstripline as well as CPW feed techniques due to self-similarity properties in the iterative fractal antenna. The monopole exhibits wideband characteristics with similar and omni-directional patterns at various resonant frequencies in azimuth plane. The planar monopole can be used for compact wideband applications. The compact behavior of the fractal antenna can be attributed to its space filling properties. The proposed fractal antenna can be fabricated on low cost FR4 substrate material. It is simple in design and finds applications in various types of compact wireless communications.

\section{ACKNOWLEDGEMENTS}

The authors would like to thank everyone, just everyone!

\section{REFERENCES}

[1] Kumar, G.; Ray, K. P.: Broadband Microstrip Antennas, Artech House, Norwood, Mass., 2003.

[2] Wong, K.L.: Compact Broadband Microstrip Antennas, John Wiley \& Sons Inc., New York, 2002.

[3] Pozar, D. M.; Schaubert, D. H.: A review of bandwidth enhancement techniques for microstrip antennas, The analysis and design of microstrip antennas and arrays, IEEE Press, New York, 1995, $157-166$.

[4] Pues, H. F., Van de Capelle, A. R.: An impedance matching technique for increasing the bandwidth of microstrip antennas. IEEE Trans. Antennas Propagat., vol. 37 (1989), 1345-1354.

[5] Agrawall, N. P.; Kumar, G.; Ray, K. P.: Wide-band planar monopole antennas. IEEE Trans. Antennas Propagat., vol. 46, no. 2 (1998), 294-295.

[6] Pozar, D. M.; Kaufman, B.: Increasing the bandwidth of a microstrip antenna by proximity coupling. Electronics Letters, vol. 23, no. 8 (1987), 368-369.

[7] Chen, Z. N.; Chia, M. Y. W.; Ammann, M. J.: Optimization and comparison of broadband monopoles, IEE Proc. Microwave Antennas Propagat., vol. 150, no. 6 (2003), 429-435.

[8] Thomas, K. G.; Lenin, N.; Sivaramakrishnan, R.: Ultrawideband planar disc monopole. IEEE Trans. Antennas Propagat., vol. 54, no. 4 (2006), 1339-1341.

[9] Rathi, V.; Kumar, G.; Ray, K. P.: Improved coupling for aperture coupled microstrip antennas. IEEE Trans. Antennas Propagat., vol. 44, no. 8 (1996), 1196-1198.

[10] Lai, K. Y. A.; Sinopoli, A. L.; Burnside, W. D.: A novel antenna for ultrawide-band applications. IEEE Trans. Antennas Propagat., vol. 40 (1992), 755-760.

[11] Anguera, J.; Puente, C.; Borja, C.: Dual frequency broadband microstrip antenna with a reactive loading and stacked elements. Progress In Electromagnetics Research Letters, vol. 10, (2009), 1-10. 
[12] Yang, X. H.; Shafai, L.: Characteristics of aperture-coupled microstrip antennas with various radiating patches and coupling slots. IEEE Trans. Antennas Propagat., vol. 43, no. 1 (1995), 72-78.

[13] Thakare, Y. B.; etal.: Super wideband fractal antenna for wireless communication, IEEE Int. conf. on wireless information technology and systems (ICWITS), Maui, Hawaii, USA, 2012.

[14] Lethakumary, B.; Menon, S. K.; Francis, P.; Anandan, C. K.; Vasudevan, K.; Mohanan, P.: Wideband microstrip antenna using hook-shape feed. Microwave and Optical Technology Letters, vol. 44, no. 2 (2005), 169-171.

[15] Thakare; Y. B.; etal.: Design of fractal patch antenna for size and radar cross-section reduction. IET Microw. Antennas Propag., vol. 4, (2010), 176-178.

[16] Y. B. Thakare (2016) "Verification of multiband characteristics in iterative fractal antenna," International Journal of Antennas (JANT), (2016), Vol. 2, no. 3, pp. 13-20.

\section{AUTHORS}

\section{YOGESH BABARAOJI THAKARE}

\section{Short Biography}

Yogesh B. Thakare (mother-Sushilabai) is passed BE E\&TC in the year 1998 with first class from VYWS College of Engg., Badnera, Amravati University (Maharashtra -India), ME E\&TC (Microwave) in the year 2006 from Govt. College of Engg., Pune, Pune University (Maharashtra-India) in first class and Ph.D. (Electronics) from Shivaji University, Kolhapur (Maharashtra- India) in 2015.He has about 15 years teaching and 02 years industrial experience. He is currently working with PVG's College of Engineering and Technology, Parvati, Pune (Maharashtra-India) as ASSISTANT

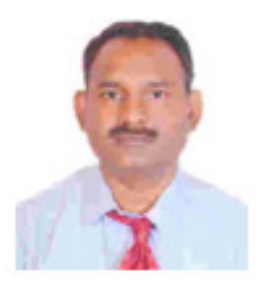
PROFESSOR in the department of electronics and telecommunication Engg. He taught major subject like wave theory and antenna, microwave engineering, semiconductor devices and technology, analogue and digital communication engineering. He has 04 international and 01 national journal and 05 international and 04 national conference publications. His current research interest is in wave propagation techniques, microstrip antenna engineering, communication engineering and semiconductor electronics. 